\title{
Vollkeramik auf einen Blick - Neuauflage jetzt auch als eBook erhältlich
}

Das Keramikhandbuch „Vollkeramik auf einen Blick“, erstmalig im Jahr 2006 erschienen, hat sich über mehrere Auflagen zu einem Standardwerk für die vollkeramische Restauration entwickelt. Zwischenzeitlich ist das Buch auch in Englisch, Französisch, Japanisch und Koreanisch erschienen und auszugsweise in chinesischen Fachmedien.

Die Autoren haben nun neue Therapielösungen pragmatisch überprüft und die 6 . deutsche Auflage mit ergänzenden Behandlungsthemen vorbereitet. So werden Restaurationstechniken mit neuen Werkstoffen wie Hybridkeramik, Verbundkeramik, zirkonoxidverstärkten Silikatkeramiken vorgestellt. Klinische Langzeiterfahrungen mit okklusionskorrigierenden Kauflächen-Veneers, vollkeramischen Adhäsivbrücken, computergestützten Verblendtechniken und implantatgetragenen Suprastrukturen wie Hybrid-Abutmentkronen aus Lithium-Disilikat fanden Eingang in das Manuskript der Neuauflage. Eine ausführliche Literaturliste mit international anerkannten, klinischen Studien $\mathrm{zu}$ konservierenden und prothetischen Versorgungen aus Vollkeramik wird dem niedergelassenen Zahnarzt gegenüber Kostenträgern wichtige Belege für den medizinischen Fortschritt in die Hand geben.

Besonders die junge Generation von Zahnärzten und Zahntechnikern bevorzugt digitale Medien und wählt sich auf Internet-Plattformen ein, um Antworten auf fachliche Fragen zu finden. Auch das eBook, aus dem Netz heruntergeladen, wird künftig ein wichtiges Medium sein. Darum hatte die AG Keramik schon vor geraumer Zeit die deutsche und englische Version des Keramikhandbuchs zum Download bereitgestellt. Der Erfolg dieser Maßnahme ist auch der Grund, dass die neue Auflage von „Vollkeramik auf einen Blick“ als deutsche und englische Editionen im eBook-Shop erhältlich sein wird.

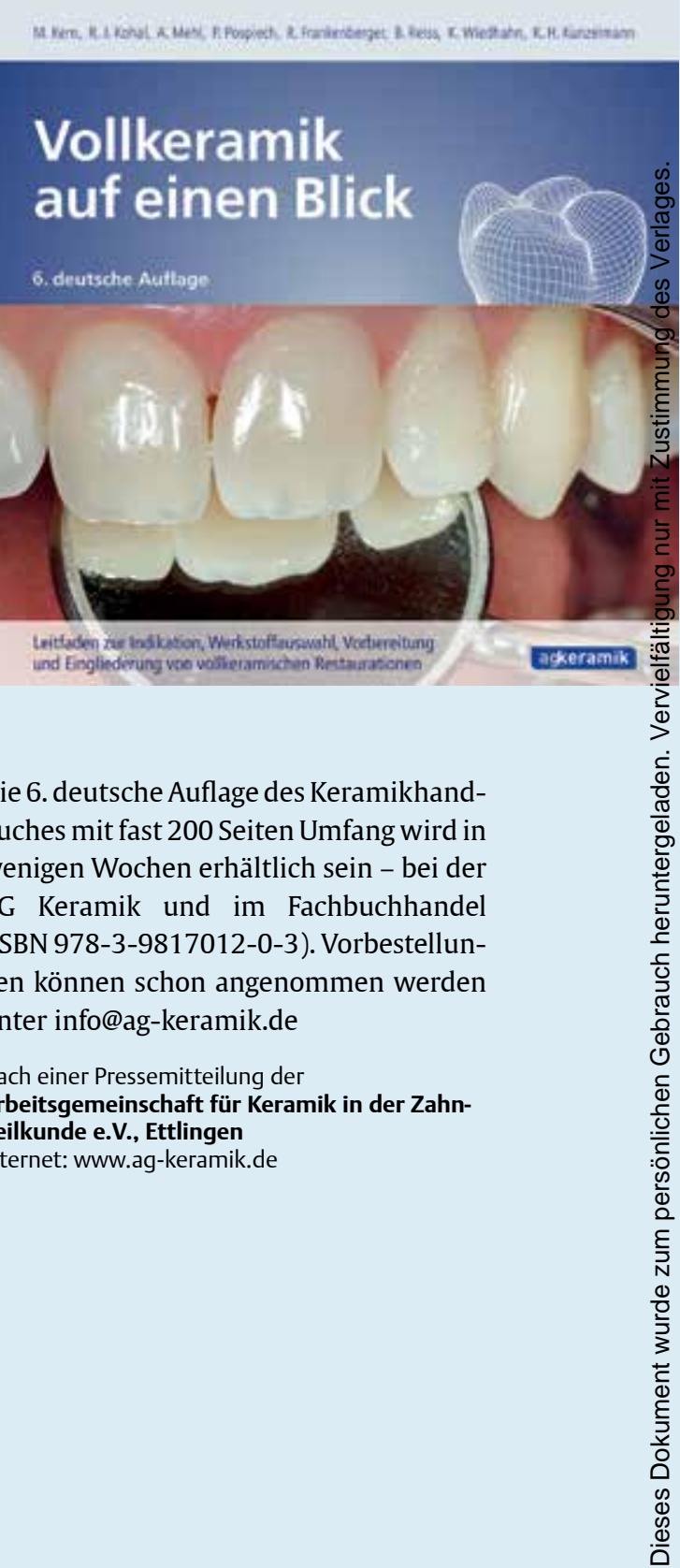

